\title{
Alterations in the lipid profiles and circulating liver enzymes in individuals infected by Schistosoma mansoni
}

\author{
Fabiana Letícia da Silva ${ }^{[1]}$, Rodrigo Pimenta Del-Rei ${ }^{[2]}$, Déborah Bittencourt Mothé Fraga ${ }^{[3]}$, \\ Leonardo Maia Leony ${ }^{[2]}$, Alina Maria Gonzaga Carlos de Souza ${ }^{[4]}$ \\ and Fred Luciano Neves Santos ${ }^{[2]}$
}

\begin{abstract}
[1]. Laboratório de Análise de Sistemas de Informações em Saúde, Instituto Aggeu Magalhães, Recife, PE, Brasil. [2]. Laboratório Avançado de Saúde Pública, Instituto Gonçalo Moniz, Salvador, BA, Brasil.

[3]. Laboratório de Interação Parasito-Hospedeiro e Epidemiologia, Instituto Gonçalo Moniz, Salvador, BA, Brasil.
\end{abstract}

[4]. Laboratório Datalab, Grupo Promedica, Salvador, BA, Brasil.

\begin{abstract}
Introduction: Portal hypertension and periportal fibrosis commonly occur in severe Schistosoma mansoni infection. Changes in lipid profile and elevated levels of circulating liver enzymes have also been described in infected individuals. The present study sought to assess the alterations in laboratory parameters associated with liver disorder in individuals infected by S. mansoni who visited a private routine laboratory service. Levels of circulating liver enzymes (gamma-glutamyl transferase [ $\gamma$-GT], aspartate transaminase [AST], alanine transaminase [ALT], and alkaline phosphatase [ALP]) and a lipid panel (total cholesterol [COL], high-density lipoprotein [HDL], low-density lipoprotein [LDL], very low-density lipoprotein [VLDL], and triglycerides [TRI]) were evaluated in both infected and non-infected individuals and relative risk was used to measure associations. Methods: Data were collected for analysis from a total of 1,078 cases identified in 379,600 individuals who submitted samples to the Datalab Laboratory (Salvador, Bahia) between 2004 and 2008. Results: S. mansoni infection led to increased circulating levels of $\gamma$-GT in both women and men, AST (women), and ALP (men). S. mansoni infection was a protective factor against increased levels of TRI, CHO, and VLDL for individuals aged 19 years or older. The results of our analysis indicate that alterations in lipid metabolism and circulating liver enzymes in asymptomatic $S$. mansoni-infected individuals might be attributed to eggs lodged in the hepatic sinusoids. Conclusions: Parasitological testing for S. mansoni should be indicated in endemic areas when this pattern of alterations is detected.
\end{abstract}

Keywords: Schistosoma mansoni. Biochemical changes. Liver enzymes. Cholesterol. Triglycerides.

\section{INTRODUCTION}

Schistosomiasis is an infection caused by a digenetic intravascular parasite that inhabits the venous portalmesenteric system in humans, where it can live up to ten years or longer, laying hundreds of eggs per day. Some of these eggs are dislocated and lodge in the hepatic sinusoids. The pathophysiological impact of Schistosoma mansoni infection has been mainly attributed to granuloma formation induced by the host cell-mediated immune response to soluble antigens secreted by parasite eggs trapped in the walls of the hepatic and intestinal vessels of infected hosts ${ }^{1}$.

While the degree of Schistosoma-associated hepatic dysfunction varies and is dependent on parasite load and host background, liver fibrosis is a common finding in advanced

Corresponding author: Dr. Fred Luciano Neves Santos.

e-mail: fred.santos@bahia.fiocruz.br

Received 27 March 2018

Accepted 2 October 2018 schistosomiasis, mostly at the sites of ongoing granulomatous reactions $^{2,3}$. Nonetheless, a wide range of liver damage has been described in both human and animal infections. These include impaired protein synthesis ${ }^{4}$, reduced lipoprotein concentrations ${ }^{5-8}$, decreased erythrocyte counts and blood indexes, neutropenia, lymphopenia and eosinophilia ${ }^{9}$, increased circulating liver enzymes levels ${ }^{10,11}$, and hemostatic abnormalities ${ }^{12,13}$. Despite the variability in clinical signs, it remains unclear whether infected individuals without clinical complaints or symptoms present a detectable degree of liver dysfunction. Therefore, we investigated the associations between $S$. mansoni infection and alterations in levels of lipoproteins and circulating liver enzymes in individuals who submitted plasma samples for routine laboratory testing in Salvador, Bahia-Brazil.

\section{METHODS}

\section{Study population and design}

The present descriptive observational study was performed to evaluate the associations between schistosomiasis and changes in lipoprotein composition or circulating liver enzymes 
in human subjects. Data were obtained from the computerized database of a private routine laboratory service (Promedica Group) in the city of Salvador, Bahia (Brazil) between January 2004 and April 2008. S. mansoni-positive, diagnosed by Lutz ${ }^{14}$ or Kato-Katz assays were included. For each infected sample, 10 helminth- and protozoa-free samples were randomly included as controls, matched by subject age, sex, and availability of biochemical analysis data.

\section{Sample processing}

Fresh stool specimens were previously analyzed by Lutz or Kato-Katz assays. The following laboratory parameters were analyzed on a Roche/Hitachi Modular System (Roche Diagnostics, IN, USA): plasma alanine transaminase (ALT; reference range: $\leq 41 \mathrm{U} / \mathrm{L}$ for males and $\leq 31 \mathrm{U} / \mathrm{L}$ for females), aspartate transaminase (AST; reference range: $\leq 37 \mathrm{U} / \mathrm{L}$ for males and $\leq 31 \mathrm{U} / \mathrm{L}$ for females), gamma-glutamyl transferase $(\gamma$-GT; reference range: $\leq 73 \mathrm{U} / \mathrm{L}$ for males and $\leq 41 \mathrm{U} / \mathrm{L}$ for females), alkaline phosphatase (ALP; reference range: $\leq 331$ $\mathrm{U} / \mathrm{L}$ for age $<17$ years and $\leq 104 \mathrm{U} / \mathrm{L}$ for age $\geq 17$ years), total cholesterol (CHO; reference range: $\leq 150 \mathrm{mg} / \mathrm{dL}$ for age $<19$ years and $\leq 200 \mathrm{mg} / \mathrm{dL}$ for age $\geq 19$ years), triglycerides (TRI; reference range: $\leq 100 \mathrm{mg} / \mathrm{dL}$ for age $<19$ years and $\leq$ $150 \mathrm{mg} / \mathrm{dL}$ for age $\geq 19$ years), and high-density lipoprotein cholesterol (HDL; reference range: $\geq 45 \mathrm{mg} / \mathrm{dL}$ for age $<19$ years and $\geq 40 \mathrm{mg} / \mathrm{dL}$ for age $\geq 19$ years). The HDL, COL, and TRI measurements were entered into a formula to estimate the very low-density lipoprotein levels (VLDL; estimated as TRI divided by 5 ; reference range: $\leq 20 \mathrm{mg} / \mathrm{dL}$ for age $<19$ years, and $\leq 30 \mathrm{mg} / \mathrm{dL}$ for age $\geq 19$ years), as well as low-density lipoprotein (LDL; estimated as COL minus HDL and VLDL; reference range: $\leq 100 \mathrm{mg} / \mathrm{dL}$ ).

\section{Statistical analysis}

Data were analyzed using SPSS version 15.0 (SPSS, Inc., Chicago, USA). Chi-square tests $\left(\mathrm{X}^{2}\right)$ were used to compare the prevalence, frequencies, and categorical data between study groups. For continuous variables, the significance of the differences between groups were tested using Mann-Whitney tests. The associations between $S$. mansoni infection and circulating hepatic enzyme levels or lipid parameters were tested by calculating the odds ratios (ORs) using the crossproduct ratios of $2 \times 2$ tables with $95 \%$ confidence intervals (CIs). P-values of 0.05 or less in two-sided testing were used as criteria for statistically significant differences.

\section{Ethical considerations}

This investigation was performed according to anonymous data without the possibility of identifying subjects; thus, there was no need for approval by an institutional review board for human research.

\section{RESULTS}

A total of 379,600 stool specimens analyzed by Lutz or KatoKatz techniques revealed S. mansoni infection in 1,078 (0.28\%) samples. The infection prevalence in the analyzed population was substantially higher in male than in female subjects $(71.8 \%$ vs. $28.2 \%, \mathrm{p}<0.001)$. Compared to the other age groups, the infection rates were highest in the age range of 31 to 40 years (Figure 1). The overall rates of $S$. mansoni infection varied from 0.50 and 0.35 in 2004 and 2005 to 0.17 and 0.16 in 2006 and 2007 , respectively. Similar rates were observed in the first four months of $2008(0.21 \%)$. Statistical analyses indicated that the monthly infection rates did not change significantly over time in this population.

The coinfection rates for intestinal parasites were 14.3\% for helminths and $40.0 \%$ for protozoa (Figure 2). Ascaris lumbricoides accounted for the highest frequency (4.9\%) among intestinal helminths, followed by hookworms (2.0\%), Strongyloides stercoralis (1.7\%), and Trichostrongylus spp $(1.0 \%)$. An association between S. mansoni and the presence of two or more helminths was detected in $3.9 \%$ of cases, with Trichuris trichiura and S. stercoralis more frequently identified than other multiple parasite infections among all categories. With respect to intestinal coinfection with protozoa, the most prevalent combination was $S$. mansoni and Endolimax nana (16\%), followed by S. mansoni and Entamoeba coli (4.0\%). Conversely, the rate of combined S. mansoni and intestinal pathogenic protozoa (Giardia lamblia and Entamoeba histolytica/dispar/moshkovskii complex) was negligible $(<0.7 \%)$. No specific diagnostic testing was performed to distinguish the species within the E. histolytica/dispar/ moshkovskii complex.

Our analysis of the geometric means of liver injury biomarkers indicated that infected women had significantly higher levels of ALT ( $p<0.01)$, AST $(p<0.01)$, and $\gamma$-GT ( $p$ $<0.01)$ compared to those in uninfected controls. For men, the levels of AST $(p<0.01), \gamma$-GT $(p=0.01)$, and ALP $(p<0.01)$ were significantly higher among infected subjects. No liver enzyme levels in either of the evaluated groups (women and men) fell outside the laboratory testing reference range. Contrary

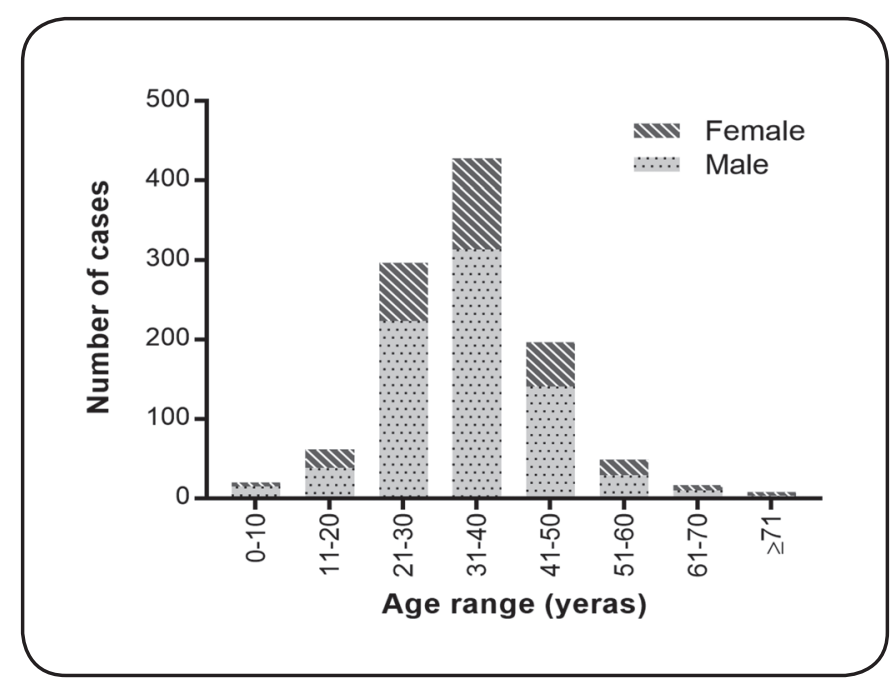

FIGURE 1: Frequency of $S$. mansoni infection, stratified according to age, in 379,600 individuals who visited a private routine laboratory service in the city of Salvador, Bahia (Brazil) between January 2004 and April 2008. 


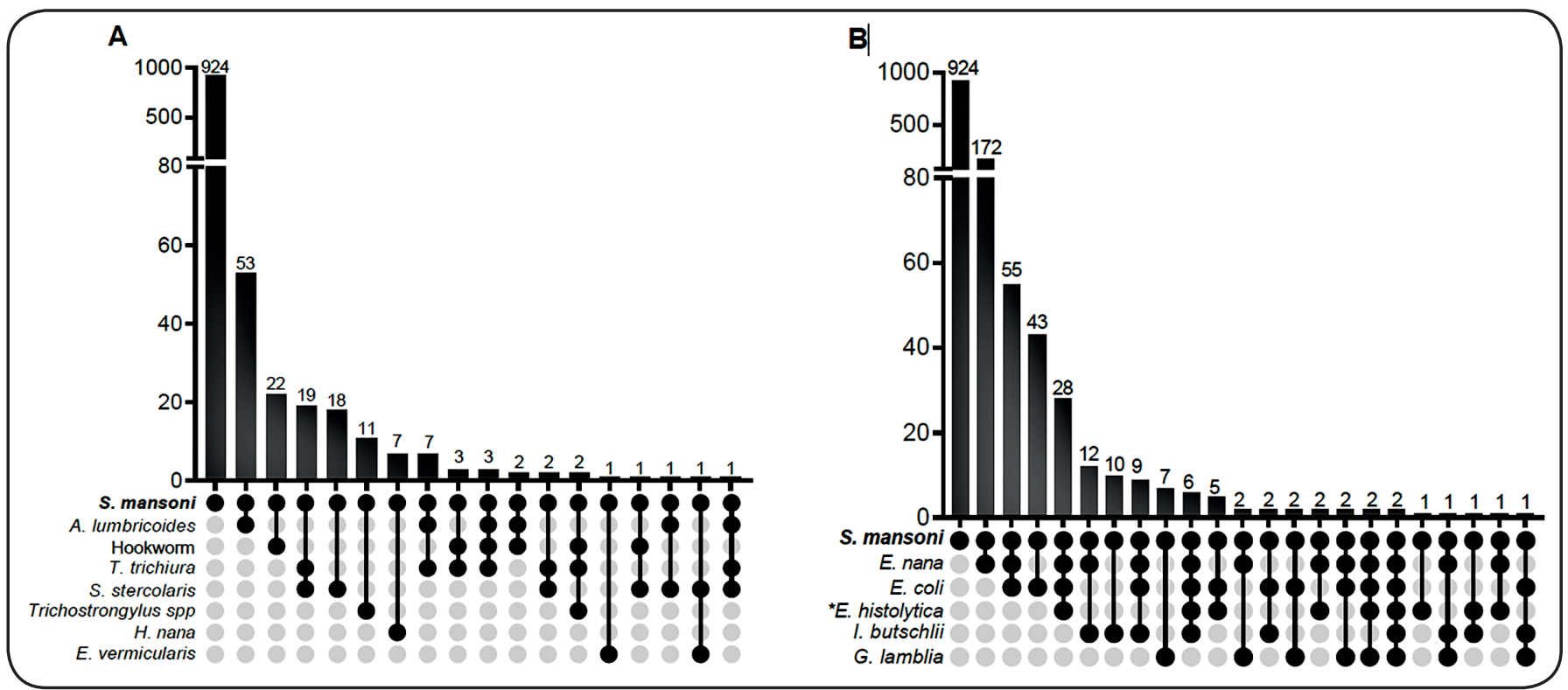

FIGURE 2: Frequency of co-infection between S. mansoni and other intestinal parasites (A - helminths; B - protozoa) in individuals who visited a private routine laboratory service in the city of Salvador, Bahia (Brazil) between January 2004 and April 2008. *E. histolytica/dispar/moshkovskii complex.

TABLE 1: Analysis of S. mansoni infection as either a risk or protective factor regarding alterations in circulating hepatic enzymes and lipid parameters, stratified according to sex or age, in individuals with or without $S$. mansoni infection who visited a private routine laboratory service in the city of Salvador, Bahia (Brazil) between January 2004 and April 2008.

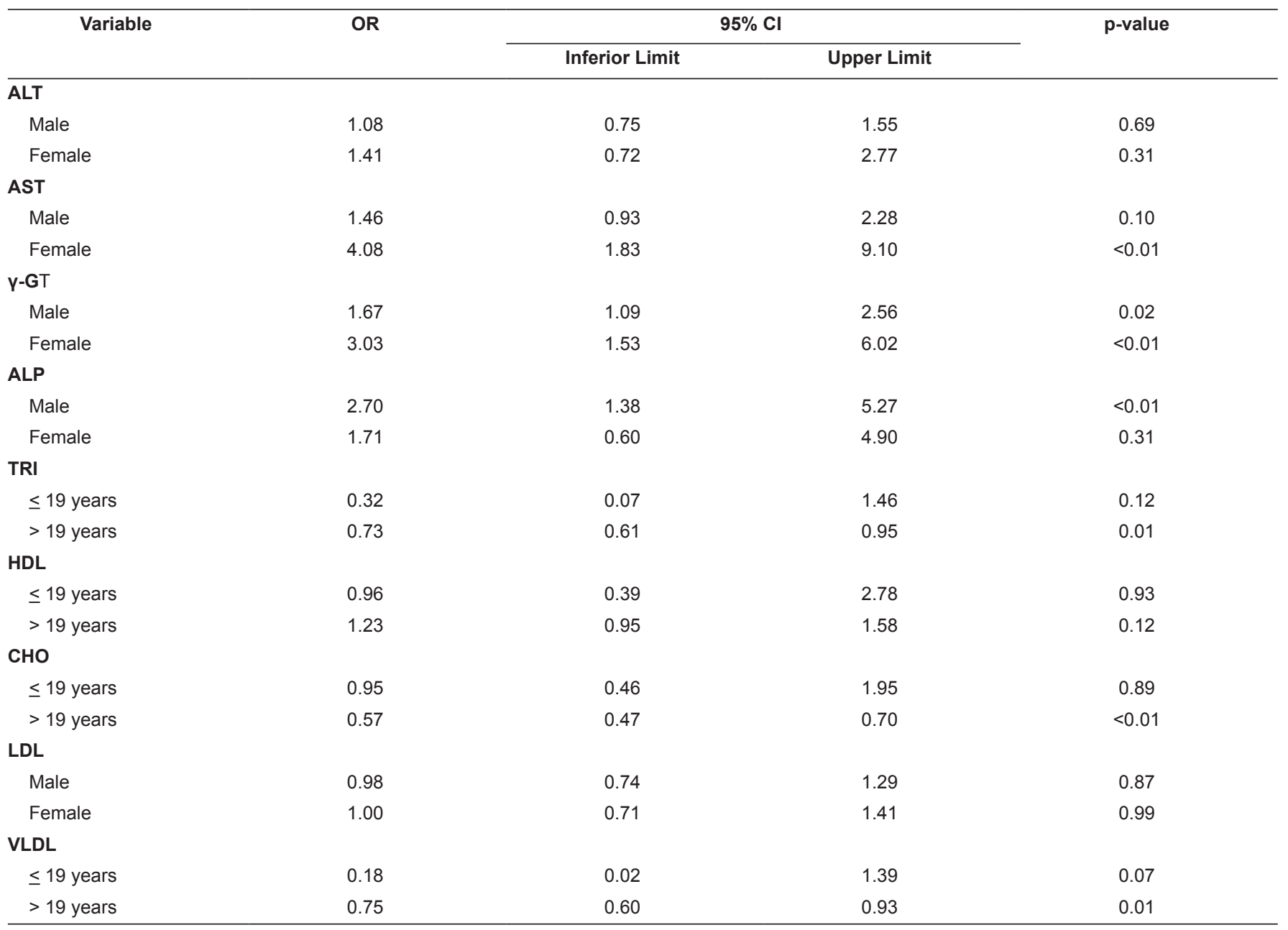

ALT: alanine transaminase; AST: aspartate transaminase; Y-GT: gamma-glutamyl transferase; ALP: alkaline phosphatase; TRI: triglycerides; HDL: highdensity lipoprotein; CHO: total cholesterol; LDL: low-density lipoprotein; VLDL: very low-density lipoprotein; 
to the observations regarding hepatic enzymes assessed by age group, significantly lower levels of lipids including TRI ( $\mathrm{p}<$ $0.01)$, HDL ( $p<0.01)$, CHO $(\mathrm{p}<0.01)$, and VLDL $(\mathrm{p}<0.01)$ were found among infected subjects aged 19 years or older compared to those in uninfected controls. Although uninfected subjects did not present higher values in relation to the values in those with schistosomiasis, the lipid levels fell below the respective reference values, except for HDL. LDL levels did not differ significantly among the infected and uninfected samples in both sexes. The levels of circulating hepatic enzymes and lipid parameters are illustrated in Figure 3.

The crude values obtained on analysis of the association between the presence of schistosomiasis infection and alterations in the markers of liver injury are presented in Table 1. This analysis suggests that $S$. mansoni infection could either increase risk or offer protection with regard to a given evaluated parameter. Accordingly, we verified that $S$. mansoni infection acts as a risk factor for increased plasma AST levels in women $(\mathrm{OR}=4.08 ; 95 \% \mathrm{CI} 1.83-9.10 ; \mathrm{p}<0.01), \gamma$-GT in women $(\mathrm{OR}=3.03 ; 95 \% \mathrm{CI} 1.53-6.02 ; \mathrm{p}<0.01)$ and $\operatorname{men}(\mathrm{OR}=$ $1.67 ; 95 \%$ CI 1.09-2.56; $\mathrm{p}=0.02)$, and ALP in men $(\mathrm{OR}=2.70$; 95\% CI 1.38-5.27; $\mathrm{p}<0.01$ ). However, S. mansoni infection was a protective factor against increased levels of TRI (OR $0.73 ; 95 \%$ CI $0.61-0.95 ; \mathrm{p}=0.01$ ), CHO (OR 0.57; 95\% CI $0.47-0.70 ; \mathrm{p}<0.01$ ), and VLDL (OR 0.75; 95\% CI 0.60-0.93; $\mathrm{p}=0.01)$ among subjects aged 19 years or older.

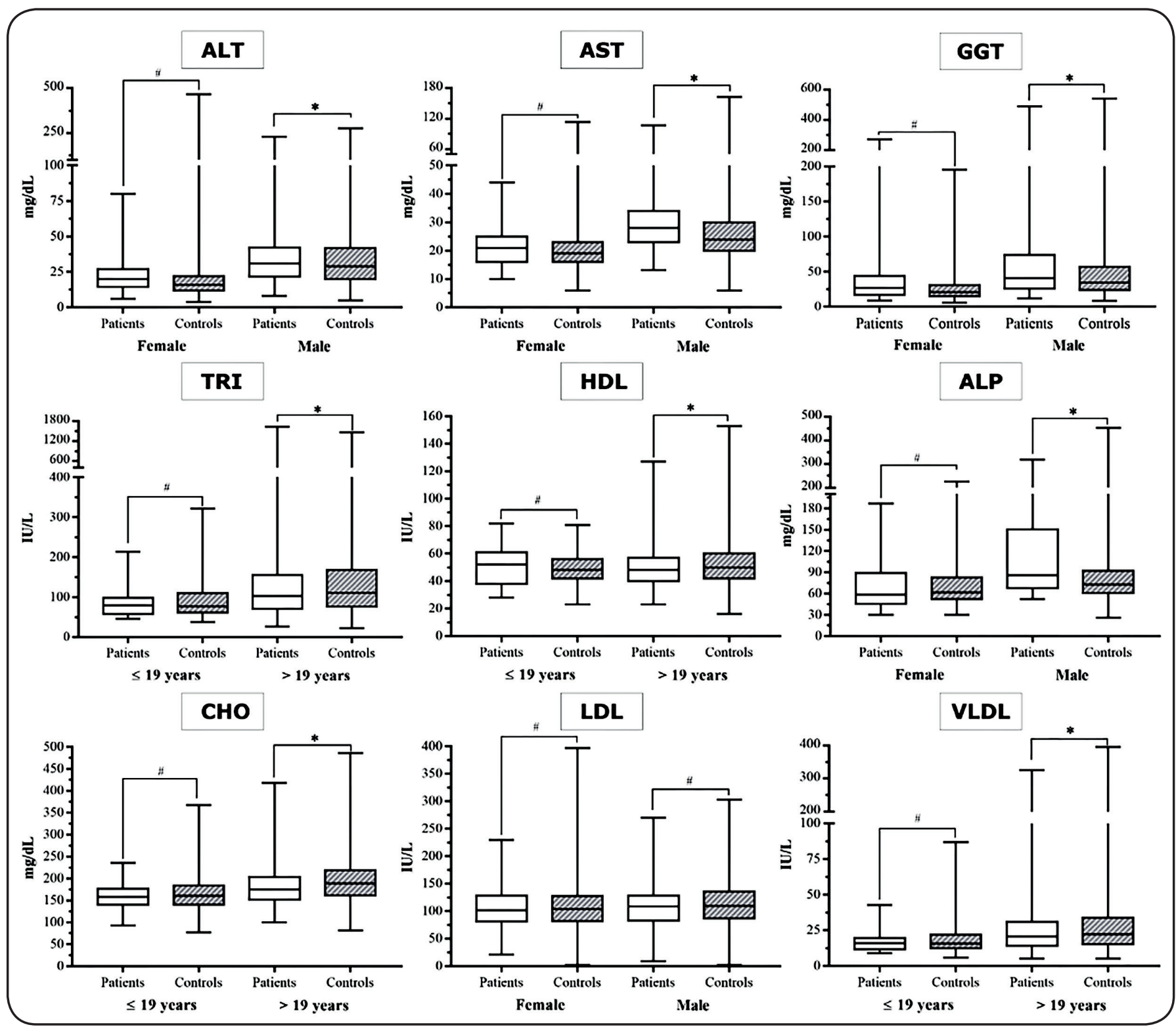

FIGURE 3: Circulating levels of hepatic transaminases and lipid parameters, stratified according to sex or age group, in individuals with or without $S$. mansoni infection who visited a private routine laboratory service in the city of Salvador, Bahia (Brazil) between January 2004 and April 2008. \#p > 0.05 ; ${ }^{*} p<0.05$. ALT (alanine transaminase), AST (aspartate transaminase), GGT (gamma-glutamyl transferase), TRI (triglycerides), HDL (high-density lipoprotein), ALP (alkaline phosphatase), CHO (total cholesterol), LDL (low-density lipoprotein), VLDL (very low-density lipoprotein). 


\section{DISCUSSION}

The present study evaluated the associations between schistosomiasis in individuals who visited a private routine laboratory service and alterations in biochemical parameters, specifically lipoproteins and circulating hepatic enzymes. Sex-associated distributions of $S$. mansoni infection in this population indicated a higher prevalence among men, a finding concordant with those of previous studies carried out in the Brazilian states of Pernambuco ${ }^{15}$, Alagoas $^{16}$, Sergipe ${ }^{17}$, and Bahia $^{18}$. The predominance of mansonic schistosomiasis in men is likely due to cultural and behavioral variables rather than male-specific susceptibility ${ }^{19}$.

Distribution analysis of schistosomiasis by age revealed infection across all evaluated groups, with the highest frequency occurring between 31 and 40 years of age. Similar results have been reported by other studies, which also indicated a higher prevalence among young adults who are more likely to be vulnerable to infection as they are the most productive and exposed age group ${ }^{20}$; i.e., they are more susceptible to infection due to their work and recreational activities.

We observed a decreasing prevalence of $S$. mansoni infection over the course of the study period. This is likely due to the implementation of the Bahia Azul Project in 1996, which deployed water supply networks and sanitary sewage systems and also implemented cleaning efforts in rivers and on beaches, resulting in significant improvements in sanitary conditions and quality of life for the population of the metropolitan region of Salvador ${ }^{21}$. These positive impacts have been detailed in studies confirming a reduced prevalence of parasitic infections in the region ${ }^{21,22}$. Moreover, the municipality's expansion of health care services, combined with the use of schistosomicidal drugs beginning in 2001, also contributed to declining rates of infection.

An association between $S$. mansoni infection and infection by other intestinal parasites was also observed, with $E$. nana infection being the most frequently occurring coinfection. Among the protozoa species that could result in disease ( $G$. lamblia and the E. histolytica/dispar/moshkovskii complex), no significant association with $S$. mansoni was detected. Coinfection involving other helminths occurred more frequently with respect to $A$. lumbricoides, hookworm, and $S$. stercoralis, which corroborates previous reports in distinct locations around the state of Bahia ${ }^{23-26}$. Despite differences in transmission mechanisms among these parasite species, their presence is nonetheless indicative of low socioeconomic status, inadequate basic sanitation, and a lack of education regarding proper hygiene.

With respect to schistosomal hepatic disease, due to its essentially mesenchymal nature, the results of liver function testing were relatively normal. Some alterations have been reported in the early stages of infection, including impaired protein synthesis, as evidenced by increased in prothrombin index ${ }^{27}$, as well as changes in circulating liver enzymes ${ }^{28}$. Hepatic manifestations originating from the deposition of eggs inside the small vessels of the liver can lead to an intense inflammatory response and subsequent functional changes ${ }^{29}$.
Liver damage can be assessed by measuring the levels of enzymes associated with bile duct ( $\gamma$-GT and ALP) or hepatocyte damage (ALT and AST). In our study, schistosomal infection induced increased circulating levels of ALT (women only), AST and $\gamma$-GT (both sexes), and ALP (men only). However, the mean values in each group remained below the reference values. It is, therefore, possible that the observed alterations in the levels of hepatic enzymes could characterize hepatic impairment in individuals infected with S. mansoni, even in the absence of clinical symptoms of the disease. To confirm whether schistosomiasis is a risk factor for increased liver enzyme levels, we analyzed the association between $S$. mansoni infection and alterations in these biomarkers. Associations between parasite exposure and increased circulating levels of AST were observed in women, in addition to $\gamma$-GT for both sexes and ALP for men. According to the literature, $\gamma$-GT is a prognostic marker of fibrosis in schistosomiasis ${ }^{30,31}$. Several mechanisms have been proposed to explain the elevation of $\gamma$-GT and ALP levels in schistosomiasis, including parasitic load, periportal fibrosis, and hepatobiliary alterations ${ }^{32,33}$. While transaminases are not considered useful prognostic markers of schistosome infection, alterations have been observed as a result of hepatic damage on a cellular level, which indicates that increases in these enzymes constitute a reliable indicator of hepatic cellular damage ${ }^{34,35}$. Accordingly, increased circulating levels of liver enzymes were observed in our sample of schistosomal individuals.

Lipid profile analysis indicated lower geometric averages for TRI, HDL, CHO, and VLDL in S. mansoni-infected individuals than in uninfected individuals aged 19 years or older. Risk association analysis indicated that schistosomiasis was a protective factor against increased plasma levels of TRI and $\mathrm{CHO}$ in this age group. According to Silva et al. ${ }^{36}$, abnormalities in lipid metabolism are commonly seen in the hepatosplenic form of schistosomiasis, particularly decreased total cholesterol, TRI and HDL levels. Experimental studies have shown that schistosomal infection inhibits atherosclerosis in addition to reducing total cholesterol levels in mice ${ }^{37,38}$, which may be explained by the fact that $S$. mansoni is unable to synthesize cholesterol required for growth and egg production $^{39}$. Additionally, schistosomiasis has been shown to lead to decreased LCAT enzyme activity, since HDL is used as a substrate in the plasma cholesterol esterification reaction ${ }^{40}$. Accordingly, our results demonstrate that schistosomiasis reduces lipid plasma levels, thereby acting as a protective factor against increased TRI and CHO in asymptomatic individuals infected with $S$. mansoni.

The limitations of the study were i) the lack of egg counts to correlate with the lipid profile and liver enzyme results, ii) the classification of S. mansoni infection based on the Lutz and/ or Kato-Katz methods since these methods lack sensitivity in lower-intensity infections, and iii) the lack of investigation of schistosomiasis-associated symptomatology in the analyzed individuals. Nonetheless, the results of our analysis indicate that alterations in lipidic metabolism and circulating liver enzymes in $S$. mansoni-infected individuals might be attributed to eggs lodged in the hepatic sinusoids. When individuals residing in 
endemic areas present this pattern of alterations in laboratory parameters, health care professionals should recommend parasitological testing for the early detection of $S$. mansoni to minimize the exacerbation of hepatic injury. However, other causes of alterations in hepatic enzymes and lipid metabolism should also be considered for differential diagnosis.

\section{Acknowledgments}

We thank Dr. George Tadeu Nunes Diniz (Fiocruz-PE) for his critical review of the manuscript and Andris K. Walter for his assistance with the English revision.

\section{Conflict of interest}

The authors declare that they have no conflict of interest.

\section{Financial Support}

The funding support was provided by Gonçalo Moniz Institute (Fiocruz-BA).

\section{REFERENCES}

1. Elsheikha HM, Hussein HS, \& Rahbar MH. Clinico-pathological effects of Schistosoma mansoni infection associated with simultaneous exposure to malathion in Swiss outbred albino mice. Acta Trop. 2008;108(1):11-9.

2. Coutinho EM, Oliveira SA, Barros AF, Silva FL, Ramos RP. Manson's schistosomiasis in the undernourished mouse: some recent findings. Mem Inst Oswaldo Cruz. 2010;105(4):359-66.

3. Vennervald BJ, Dunne DW. Morbidity in schistosomiasis: an update. Curr Opin Infect Dis. 2004;17(5):439-47.

4. Abdel-Rahim IM, Kaiser C, Homeida M, Elsheikh M, Schmidt E, Ehrich $\mathrm{JH}$, et al. Enzyme activities and protein concentrations in serum of patients with hepatosplenic schistosomiasis. Trop Med Parasitol. 1990;41(3):262-4.

5. el-Marzouki ZM, Amin AM. Changes in serum lipids of mice experimentally infected with Schistosoma mansoni. J Egypt Soc Parasitol. 1997;27(2):419-29.

6. Muller E, Rosa Brunet L, Fried B, Sherma J. Effects on the neutral lipid contents of the liver, ileum and serum during experimental schistosomiasis. Int J Parasitol. 2001;31(3):285-7.

7. $\mathrm{Xu} \mathrm{X}$, Caulfield JP. Characterization of human low density lipoprotein binding proteins on the surface of schistosomula of Schistosoma mansoni. Eur J Cell Biol. 1992;57(2):229-35.

8. Amaral KB, Silva TP, Malta KK, Carmo LA, Dias FF, Almeida MR, et al. Natural Schistosoma mansoni infection in the wild reservoir Nectomys squamipes leads to excessive lipid droplet accumulation in hepatocytes in the absence of liver functional impairment. PLoS One. 2016.11(11):e0166979.

9. Mahmoud EA, Elbessoumy AA. Hematological and biochemical effects of curcumin in Schistosoma mansoni infested mice. Assiut Vet Med. 2014;60(142):184-95.

10. Barreto AV, Alecrim VM, Medeiros TB, Domingues AL, Lopes EP, Martins JR, et al. New index for the diagnosis of liver fibrosis in Schistosomiasis mansoni. Arq Gastroenterol. 2017;54(1):51-6.

11. Salah LA, Kheireldin AA, Mansour MM, Hussein F. Levels of some serum enzymes in patients with schistosomiasis. J Trop Med Hyg. 1976;79(12):270-4.
12. Tanabe M. Haemostatic abnormalities in hepatosplenic schistosomiasis mansoni. Parasitol Int. 2003;52(4):351-9.

13. Correia MC, Domingues AL, Lacerda HR, Santos EM, Machado $\mathrm{CG}$, Hora V, et al. Platelet function and the von Willebrand factor antigen in the hepatosplenic form of schistosomiasis mansoni. Trans R Soc Trop Med Hyg. 2009;103:1053-8.

14. Lutz, A. O Schistosomum mansoni e a schistosomatose segundo observações, feitas no Brasil, pelo Dr. Adolpho Lutz. Mem Inst Oswaldo Cruz. 1919;11:37-43.

15. Gomes EC, Leal-Neto OB, Oliveira FJ, Campos JV, Souza-Santos $\mathrm{R}$, Barbosa CS. Risk analysis for occurrences of schistosomiasis in the coastal area of Porto de Galinhas, Pernambuco, Brazil. BMC Infect Dis. 2014;14:101.

16. Palmeira DC, Carvalho AG, Rodrigues K, Couto JL. Prevalência da infecção pelo Schistosoma mansoni em dois municípios do Estado de Alagoas. Rev Soc Bras Med Trop. 2010;43(3):313-7.

17. Rollemberg CV, Silva MM, Rollemberg KC, Amorim FR, Lessa NM, Santos MD, et al. Predicting frequency distribution and influence of sociodemographic and behavioral risk factors of Schistosoma mansoni infection and analysis of co-infection with intestinal parasites. Geospat Health. 2015;10(1) 303.

18. Guimarães IC, Tavares-Neto J. Transmissão urbana de esquistossomose em crianças de um bairro de Salvador, Bahia. Rev Soc Bras Med Trop. 2006;39(5):451-5.

19. Pereira VV, Conceição AD, Maximiano LH, Belligoli LD, Silva ES. Laboratory diagnosis of amebiasis in a sample of students from southeastern Brazil and a comparison of microscopy with enzymelinked immunosorbent assay for screening of infections with Entamoeba sp. Rev Soc Bras Med Trop. 2014;47(1):52-6.

20. Raso G, Vounatsou P, McManus DP, N'Goran EK, Utzinger J. A Bayesian approach to estimate the age-specific prevalence of Schistosoma mansoni and implications for schistosomiasis control. Int J Parasitol. 2007;37(13):1491-500.

21. Barreto M L, Genser B, Strina A, Teixeira MG, Assis AM, Rego $\mathrm{RF}$, et al. Effect of city-wide sanitation programme on reduction in rate of childhood diarrhoea in northeast Brazil: assessment by two cohort studies. Lancet. 2007;370(9599):1622-8.

22. Santos FL, Souza AM, Soares NM. Hookworm and threadworm infections and their association with hemoglobin and eosinophil concentrations in residents of Salvador-Bahia, Brazil. Rev Inst Med Trop São Paulo. 2013;55(4):233-8.

23. Prado MS, Barreto ML, Strina A, Faria JA, Nobre AA, Jesus SR. Prevalência e intensidade da infecção por parasitas intestinais em crianças na idade escolar na Cidade de Salvador (Bahia, Brasil). Rev Soc Bras Med Trop. 2001;34(1):99-101.

24. Santos FL, Cerqueira EJ, Soares NM. Comparison of the thick smear and Kato-Katz techniques for diagnosis of intestinal helminth infections. Rev Soc Bras Med Trop. 2005;38(2):196-8.

25. Santos-Júnior GO, Silva MM, Santos FL. Prevalência de enteroparasitoses em crianças do sertão baiano pelo método de sedimentação espontânea. Rev Patol Trop. 2006;35(3):209-16.

26. Santos LP, Santos FL, Soares NM. Prevalência de parasitoses intestinais em pacientes atendidos no Hospital Universitário Professor Edgar Santos, Salvador-Bahia. Rev Patol Trop. 2007;36(3):237-46.

27. Camacho-Lobato L, Borges DR. Early liver dysfunction in schistosomiasis. J Hepatol. 1998;29(2):233-40.

28. el-Haieg MO, Enein MM, Mustafa MA, el-Khodary MI, Refaat MA, Ibrahim IA, et al. Studies on certain serum enzymatic activities in hepatosplenic bilharziasis. Egypt J Bilharz. 1978;5(1-2):19-28. 
29. Pearce EJ, MacDonald AS. The immunobiology of schistosomiasis. Nat Rev Immunol. 2002;2(7):499-511.

30. Kardorff R, Gabone RM, Mugashe C, Obiga D, Ramarokoto $\mathrm{CE}$, Mahlert C, et al. Schistosoma mansoni-related morbidity on Ukerewe Island, Tanzania: clinical, ultrasonographical and biochemical parameters. Trop Med Int Health. 1997;2(3):230-9.

31. Souza MR, Toledo CF, Borges DR. Thrombocytemia as a predictor of portal hypertension in schistosomiasis. Dig Dis Sci. 2000;45(10):1964-70.

32. Barreto VS. Alkaline phosphatase in schistosomiasis. Ann Intern Med. 1971;74(3):450-1.

33. Vianna MR, Gayotto LC, Telma R, Santos M, Alves VA, Fukushima $\mathrm{J}$, et al. Intrahepatic bile duct changes in human hepatosplenic schistosomiasis mansoni. Liver. 1989;9(2):100-9.

34. Aquino RT, Chieffi PP, Catunda SM, Araújo MF, Ribeiro MC, Taddeo EF, et al. Hepatitis B and C virus markers among patients with hepatosplenic mansonic schistosomiasis. Rev Inst Med Trop São Paulo. 2000;42(6):313-20.
35. Fontana RJ, Lok AS. Noninvasive monitoring of patients with chronic hepatitis C. Hepatology. 2002;36(5 Suppl 1):S57-64.

36. Silva SN, Oliveira KF, Brandt CT, Lima VL. Estudo dos lipídios em jovens portadores de esquistossomose hepatoesplênica submetidos a tratamento cirúrgico. Acta Cir Bras. 2002;17(4):251-7.

37. Doenhoff MJ, Stanley RG, Griffiths K, Jackson CL. An antiatherogenic effect of Schistosoma mansoni infections in mice associated with a parasite-induced lowering of blood total cholesterol. Parasitology. 2002;125(Pt 5):415-21.

38. Stanley RG, Jackson CL, Griffiths K, Doenhoff MJ. Effects of Schistosoma mansoni worms and eggs on circulating cholesterol and liver lipids in mice. Atherosclerosis. 2009;207(1):131-8.

39. Meyer F, Meyer H, Bueding E. Lipid metabolism in the parasitic and free-living flatworms, Schistosoma mansoni and Dugesia dorotocephala. Biochim Biophys Acta. 1970;210(2):257-66.

40. Owen JS, Gillett MP. Lecithin:cholesterol acyltransferase deficiency associated with hepatic schistosomiasis mansoni. Scand J Clin Lab Invest. 1978;38(Suppl 150):194-8. 